Dr. Dushman spent some thirty years compiling data on all aspects of the fundamentals of vacuum techniques. Now he has died it is unlikely that there is anywhere a successor with the breadth of knowledge and experience to undertake single-handed the writing of such a comprehensive treatise. Fortunately, the revision of this classic text has been entrusted to a team of eight specialists under the editorship of Dr. J. M. Lafferty, all of whom are members of the research staff of the General Electric Research Laboratory, Schenectady, N.Y., where Dushman was formerly assistant director. Sometimes books written by a team are badly co-ordinated and vexatious to the reader. Happily, this criticism certainly cannot be levelled at this second edition. The editor has most successfully woven the contributions of his team into the original text of Dushman to produce an up-to-date version which still retains the virtues of clear writing, comprehensiveness, full referencing and orderly development of the first edition.

As would be expected from its title, little appears in the book about applications. However, more detail of the scientific aspects of the design of very large vacuum plants would have been welcome. Again, stainless steel-increasingly used in modern ultra-high vacuum technology-receives little attention. Accounts of the kinetic theory are a little obscured by repetition of formulæ in various units, which would be preferably avoided by giving only basic formulæ and appropriate conversion tables.

But this is an excellent book; Dushman would have been proud of it. Like his own first edition, it will be indispensable for many years to come.

JoHN YARWOOD

\section{MEASURING RADIOACTIVITY IN THE HUMAN BODY}

\section{Whole-Body Counting}

Proceedings of the Symposium held by the International Atomic Energy Agency at the Neue Hof burg, Vienna, 12-16 June, 1961. Pp. viii + 535. (Vienna: International Atomic Energy Agency; London: H.M. Stationery Office, 1962.) $60 s$.

$\mathrm{T}$ $\mathrm{HE}$ whole-body counter is becoming increasingly important as a tool in health physics, to determine the amounts of radioactive materials which have entered the human body, generally as a result of an accident. It is, however, of greater interest than it appears to be at first sight; for example, its use can considerably extend many in vivo tracer experiments and the causes of obesity and similar disorders can be investigated by using it to determine the potassium -40 content of the body and hence the fat-lean ratio.

The earliest instruments of this type used ionization chambers, with low efficiency and poor geometry, but the development of the scintillation counter has brought tremendous advantages. Sodium iodide crystal counters have a higher $\gamma$-efficiency, and permit very good energy resolution for spectrometry but are restricted in size, thus limiting the solid angle. The geometry can be greatly improved by using plastic or liquid scintillators which are virtually unlimited in size, and a $4 \pi$ counter using a liquid scintillator has already been constructed; these scintillators, however, have poor energy resolution.

Needless to say, the whole-body counter is very expensive, and considerable thought must be given to its siting, particularly in relation to the natural back. ground and the type of shielding to be used. As a result, we are never likely to see large numbers of these instruments, but we should aim at making full use of those that are available, both for emergency measurements and for research.

Up to the present time, the method has been feasible only for measuring $\gamma$-emitters, but recent work in Sweden shows some promise of measuring body burdens of pure $\beta$-emitters by means of the associated bremsstrahlung. Another new develop. ment is the use of computer techniques for storage and processing of the data obtained in $\gamma$-spectrometry.

These are some of the problems discussed in detail in Whole-Body Counting. Those already in the field will probably be aware of progress elsewhere, but they will almost certainly find this book to be a useful survey. It will also be of considerable interest to health physicists, and to many users of radioisotopes who may well be surprised at the problems and possibilities of this type of instrument.

H. D. Evans

\section{ELECTRON MICROSCOPY}

\section{Traité de Microscopie Électronique}

Sous la direction de Claude Magnan, avec la collaboration de Nina Carasso, Pierre Favard, Charles Fert, Angès Oberlin, Adrien Saulnier et Cyril Tchoubar. Tome 1 : Pp. viii + 1-650. Tome 2 : Pp. viii +6511301+33 planches. (Paris: Hermann, 1961.) 2 volumes $300 \mathrm{NF}$

THINK of the most sumptuously produced scientific book you have ever seen-on any subject, animal, vegetable or mineral--double it, insert 33 full-page, glazed photographic prints, and you have the only complete treatise on electron microscopy in any language. The only comparable work has been Electron Optics and the Electron Microscope (1946) by a team colloquially known in the United States as 'We, the People'. But Zworykin, Morton, Ramberg, Hillier and Vance numbered only five and contained the subject within 760 pages. with very little on practical applications. The new French team of seven have need of almost twice the space; and at that, the electron optical part has been condensed into much less compass than the Americans allowed themselves; it is now the applications which have filled out to more than half the work.

Volume 1 describes the physical principles of elec. tron microscopy and Volume 2 its applications. In addition to the basic optics, much attention is also directed to instrumentation - the theory of electron interaction with matter (including photography) as well as detailed descriptions of the many different types of electron microscope and their accessories. There are special chapters on the microscopy of solid surfaces, on electron interference effects and on electron diffraction, and on the aspects of crystallography with which these phenomena are concerned. Methods of specimen preparation are fully dealt with, and the first volume is completed by surveys of particle size and shape determinations and of physical and chemical transformations that can be followed by electron microscopy.

Volume 2 is devoted to the special preparation techniques for metallurgical and biological material, and surveys of the new knowledge which they have 